\title{
Entre experiências e diferenças nas mídias digitais: modos de uso da \#seráqueéracismo*
}

Renata Baboni**

\section{Resumo}

A pesquisa investigou a relação entre os modos de uso e os processos de identificação em torno da \#seráqueéracismo no Twitter. Para isso, abordou como as diferenças sociais foram articuladas nas discursividades sobre "experiências de racismos", por meio de análise dos conteúdos publicados nas mídias digitais $e$ entrevistas semiestruturadas com xs influenciadorxs, produtorxs de narrativas muito compartilhadas; e utilizou os eixos analíticos "experiências" e "diferenças", por meio da Teoria Queer. Nessas negociações sobre diferenças, a hashtag - modo de comunicação sobre si - foi muito usada, tanto para demonstrar a prática contestatória da percepção de certa norma racista vigente, em algumas narrativas, quanto para gerar uma discussão sobre a falta de reconhecimento e a inferiorização de certas "experiências sobre racismos" relatadas, em outras narrativas. Nesse jogo de ambivalências das experiências, ora foram reproduzidas as normalizações sobre diferenças, por meio de demarcações de posicionalidades e estereotipações de sujeitos e subjetividades, ora foram contestadas. Também foi frequente o relato do "racismo $\mathrm{dx}$ outrx", vinculado ao desejo de reconhecimento social e subjetivo que rege esses usos (que, em muitos casos, foi negado à pessoa negra, conferindo-lhe vitimização e responsabilização sobre a existência das "experiências sobre racismos" relatadas).

Palauras-chave: Diferenças, Mídias Digitais, \#Seráqueéracismo, Teoria Queer, Hashtag.

* Recebido em 28 de novembro de 2017, aceito em 11 de dezembro de 2019. ** Doutoranda em Psicologia Clínica, PUC-SP. Pesquisadora do Núcleo de Estudos da Subjetividade da PUC-SP, São Paulo, SP, Brasil. renatababoni@gmail.com / https://orcid.org/0000-0001-5789-6715 
Between Experiences and Differences in Digital Media: Modes of Using \#Seráqueéracismo

\begin{abstract}
This study investigated the relationship between modes of use and identification processes related to \#seráqueéracismo on Twitter. It examined how social differences were articulated in the discursivities about "experiences of racism", by analyzing contents published on digital media. Semi-structured interviews were conducted with influencers and producers of intensely shared narratives, using the analytical foci of "experiences" and "differences", based on Queer Theory. In these negotiations about differences, the hashtag - a communication mode about itself - was intensely used to both demonstrate the controversial practice of perceiving a specific dominant racist norm, in some narratives, or to generate a discussion about a lack of recognition and inferior treatment of certain "experiences about racisms" reported in other narratives. In this interplay of ambivalences of experiences, normalizations of differences were at times reproduced through demarcations of positions and stereotyping of subjects and subjectivities, and at other times were contested. The reports of "the racism of others" was also very frequent, directly linked to a desire for social and subjective recognition that guide these usage modes (which, in many cases, was denied to black people, who were conferred to victimization and accountability for the existence of the "racist experiences " reported).
\end{abstract}

Keywords: Differences, Digital Media, \#Seráqueéracismo, Queer Theory, Hashtag. 


\section{\# Hashtag-se!}

Este texto resulta de uma pesquisa ${ }^{1}$ que abordou a relação entre os modos de uso e os processos de identificação em torno da hashtag seráqueéracismo, no Twitter, por meio do estudo dos eixos analíticos "experiências" e "diferenças".

"Experiências", na qualidade de eixo analítico, não se refere à significação - como evidência, reflexo do real ou ponto originário de explicação incontestável - das narrativas relatadas pelxs participantxs da pesquisa (Scott, 1998). Experiência é aqui compreendida como lugar de formação dos sujeitos, marcados por processos sociais e subjetivos, e como modo de entendimento das operações em torno das diferenças sociais (Scott, 1998:301).

No mesmo sentido, o eixo analítico "diferenças", contextualmente contingente, é acionado na direção proposta por Avtar Brah (2006), que elucida a necessidade de entendimento do modo como articulam-se raça, gênero, sexualidade e classe social no interior de uma dinâmica de sociabilidade, como exposto nas discursividades elencadas, a partir da experiência empírica - e em consonância também com Moutinho (2014), que analisa os distintos marcadores sociais das diferenças de maneira articulada, com enfoque específico nas identidades subjetivas, no espaço de agência e na inserção em novas redes de sociabilidade.

Assim, a compreensão de processos de identificação inscritos nas experiências comuns (compartilhadas) relativas a diversos eixos específicos de diferenciação necessita de uma problematização das diferenças como modos de ser nestas interações entre as experiências, as subjetividades (onde o sujeito experimenta processos de identificações e lhes atribui sentidos) $e$ as relações sociais (Brah, 2006).

Caracterizado como uma ferramenta de microblog ou de micromensagens (Recuero; Zago, 2009), o Twitter possui o recurso das hashtags, isto é, indexadores de tópicos e/ou palavras-chave

${ }^{1}$ Este artigo deriva da minha dissertação de mestrado, realizada entre 2015 e 2017 no programa de Pós-Graduação em Sociologia da Universidade Federal de São Carlos. 
que atuam como potentes marcadores temáticos e como modo objetivo de situar acontecimentos. Ao agregar, em um único fluxo, todas as publicações feitas com a mesma hashtag, a plataforma possibilita observar uma aglutinação coletiva pautada em identificações temáticas daquelxs que utilizam determinada hashtag para participar da discussão de um tema e divulgar informações em "tempo real" (Santaella; Lemos, 2010:108-109).

Como linguagem tecnológica contemporânea, os seus usos envolvem a mínima compreensão das dinâmicas de sentidos comunicacionais que vão sendo atribuídas pelxs próprixs participantes durante seus processos de utilização, especialmente nos casos de campanhas que incentivam o uso coletivo dessas hashtags, como as voltadas a relatos de experiências sobre temáticas sociais específicas - entre elas, a \#seráqueéracismo.

Dentre os fatores que influenciam diretamente na adesão à determinada hashtag, estão: o seu uso por parte de sujeitos específicos (nomeados aqui como influenciadorxs, participantes que possuem alto potencial de influência sobre outrxs e posição social prestigiosa nas mídias digitais, também facilitada pela plataforma) e associações entre a hashtag e demais assuntos de destaque midiático no momento em que estão sendo utilizados. Nesse sentido, os assuntos mais mencionados do momento no Twitter (via hashtag) são chamados de trending topics $e$ permanecem ranqueados, como destaque, na página inicial da plataforma.

Os modos de utilização das hashtags nas mídias digitais variam ainda de acordo com a plataforma on-line envolvida, $e$ uma hashtag pode veicular-se a partir de usos inventivos, além do seu originário (classificatório-temático, cunhado no Twitter). Assim, elas atuam também como potencializadores $e$ amplificadores de novas camadas de sentidos comunicacionais nas mídias digitais em cada situação específica de uso.

Portanto, diferentes meios comunicacionais produzem modos distintos de subjetivação, e este processo de organização, seleção, participação/envolvimento (inclusive afetivo) e produção de informações por parte dxs sujeitos envolvidxs - favorecido 
pelas tecnologias (como no caso da otimização do acesso a todas as postagens feitas com a mesma hashtag) - está diretamente relacionado às experiências dxs produtorxs de conteúdo $e$ às experiências dxs leitorxs. Além disso, potencializa aspectos expansivos de expressividade comunicacional nesses modos de uso específicos das hashtags. Nesse sentido, a popularidade nas mídias digitais está atrelada ao interesse e ao grau de envolvimento de seus/suas participantes, e essa relação entre os conteúdos midiáticos e xs participantes ocorre especialmente por meio de identificações (Miskolci, 2011).

Por outro lado, é preciso considerar o contexto desigual do acesso às mídias digitais no Brasil, que ainda é garantido preponderantemente para a classe média, letrada, jovem $e$ residente em região urbana. Esse dado aponta para uma reatualização das desigualdades sociais, econômicas e tecnológicas nessa configuração on-line, apesar de também haver um aumento exponencial de distribuição e acessos a cada ano no Brasil (Miskolci, 2011).

Diversxs autorxs endossam a discussão de que as produções midiáticas brasileiras, especialmente os veículos de massa, de forma geral, não são neutros na propagação de saberes relacionados às diferenças (Silva, 2015; Beleli, 2014; Pelúcio, 2014), pois carregam valores culturais e propagam normas sociais que reatualizam o modelo heteronormativo/heterorreprodutivo da sociedade brasileira (Miskolci, 2014). Por outro lado, as mídias digitais também "permitem a inserção de pessoas que antes eram relegadas a um limbo social" (Miskolci, 2011:20), possibilitando novos agenciamentos discursivos nesse sentido.

A associação entre estudos sobre subjetividades, mídias digitais e diferenças é pouco frequente na literatura sociológica brasileira, particularmente em relação aos usos das hashtags no Twitter, fator que corrobora para a concretização desta pesquisa. Definiu-se aqui, como objetivo principal, investigar os modos de usoe os processos de identificação em torno da \#seráqueéracismo no Twitter $e$ como estes se articulam $e$ negociam com as "diferenças" em suas demandas discursivas voltadas a relatos de 
"experiências sobre racismos". Especificamente, buscou-se: compreender as principais motivações dxs participantxs $e$ influenciadorxs em relação ao uso da hashtag voltado ao relato das experiências sobre racismos (por meio de análise de suas postagens no Twitter e de entrevistas semiestruturadas com estxs sujeitos); analisar as narrativas e suas demandas, que ancoraram as "experiências sobre racismos", relatadas a partir do uso da hashtag (tanto dxs influenciadorxs quanto dxs demais participantes), sob os eixos analíticos das experiências e das diferenças (concebidas de modo articulado, na relação entre gênero e/ou sexualidade e/ou raça e/ou classe social).

\section{\#Seráqueéracismo}

A metodologia consistiu na realização de revisões bibliográficas e abordagem empírica (entrevistas com seis influenciadorxs) e observação sistemática das mídias digitais (mapeamento descritivo-analítico das narrativas no Twitter).

A análise dessas postagens foi feita sobre todos os tweets que utilizaram a \#seráqueéracismo em modo público (5153 tweets) desde 5 de dezembro de 2015 até a data do seu declínio de uso (12 de julho de 2016), com ênfase no seu conteúdo (tanto o das postagens diretas quanto o das postagens retweetadas produzidos pelxs influenciadorxs). Todos os tipos de conteúdos das postagens que acompanharam o uso da hashtag foram analisados - textos, links, imagens e vídeos - mesmo quando direcionados a outras redes sociais on-line.

Além da observação sistemática das publicações feitas em modo público, para relatar experiências sobre racismos, também foram realizadas entrevistas qualitativas semiestruturadas, a partir da preparação de um roteiro prévio relativo ao foco do estudo: as motivações de usos e os processos de identificações dxs influenciadorxs em torno da hashtag.

Seis influenciadorxs participantes das entrevistas foram informados sobre os seus objetivos e concederam autorização 
prévia para identificação neste trabalho ${ }^{2}$, que buscou compreender as motivações, os sentidos e os objetivos atribuídos à produção das narrativas relacionadas às suas experiências. As empresas Audiense e $V$-tracker colaboraram no acesso, monitoramento e sistematização das informações utilizadas.

Em resumo, foram analisados todos os conteúdos discursivos de tweets realizados com a hashtag (5153 tweets publicados por 2200 perfis) e com demais informações, adicionais. Assim, a análise dessas postagens foi feita durante e após a observação e a sistematização dessas informações. Com exceção $\mathrm{dxs}$ influenciadorxs que aceitaram participar da pesquisa, os demais perfis que realizaram postagens com a hashtag não tiveram conhecimento de que estavam sendo estudados - visto a recorrência de retweets reproduzidos (baixa quantidade de publicações diretas) e a ampla difusão de postagens na rede online. Todo o conteúdo exposto neste trabalho foi retirado da busca feita no Twitter e nas ferramentas citadas com a hashtag nas postagens realizadas e disponibilizadas on-line em modo público pelos perfis que efetuaram as publicações.

\section{Ditos e não ditos sobre a hashtag}

\section{Fenômeno \#Seráqueéracismo}

$\mathrm{O}$ maior envolvimento dxs participantes com a hashtag ocorreu no mês de dezembro, especialmente na primeira semana após a sua criação, dia 5 de dezembro de 2015. Nos primeiros dias de uso (5 e 6 de dezembro), foram realizadas 3 postagens (duas publicações do criador da hashtag e um retweet) e 150 postagens (58 tweets próprios e 92 retweets), respectivamente. As hashtags, em geral, possuem um período de pico, seguido por um declínio dos seus usos, embora ainda continuem sendo utilizadas posteriormente, mas com menor frequência. Esse é o caso da

\footnotetext{
2 Xs demais participantes foram estudadxs por meio dos seus tweets, e optei, neste artigo, por não identificar os nomes dos perfis que realizaram tais publicações, apesar de todos estarem em modo público.
} 
\#seráqueéracismo, raramente utilizada atualmente. Os dias de pico da hashtag (os de maior número de publicações associadas ao seu uso) foram 7 e 8 de dezembro de 2015, que totalizaram 2694 e 1148 tweets publicados, respectivamente. Os tweets foram potencialmente vistos 12.042 vezes.

Os usos mais frequentes da \#seráqueéracismo foram via retweets (compartilhamentos de publicações de sujeitos influenciadorxs, que refletiram em $68 \%$ das postagens feitas no total com a hashtag), ressaltando um processo de identificação coletivo em relação aos modos de uso e conteúdos destxs influenciadorxs. Já menos frequentes foram as postagens de relatos e produções de conteúdos pessoais diretos/autorais, feitos pelxs participantes (acompanhados e conjugados ou não com textos, fotos, vídeos e links), que corresponderam a $31 \%$, sucedidos por replies/respostas $(0,97 \%)$ e menções $(0,89 \%)$.

Com a proposta de investigar a relação entre os modos de uso da hashtag seráqueéracismo e os processos de identificação relacionados às experiências relatadas pelxs participantxs em torno das diferenças, foram elencados quatro pontos centrais dos processos e dinâmicas de usos observados em torno dessa hashtag. 1) A influência do criador da hashtag e suas motivações; 2) Xs influenciadores centrais da maioria das pautas/conteúdos temáticos e dos modos de uso dessa hashtag, 3) Demais hashtags influenciadoras e seus contextos; 4) A influência de experiências nas próprias mídias digitais, que delimitaram novos modos de uso da hashtag.

\section{O criador, suas motivações e influências (@AiraOCrespo)}

Criada no Twitter pelo grafiteiro Airá O Crespo, no dia 5 de dezembro de 2015, sob inspiração e resposta à execução de cinco jovens negros alvejados brutalmente com 111 tiros por policiais no Rio de Janeiro, a hashtag seráqueéracismo surgiu com o objetivo de incentivar relatos de "experiências de racismos" cotidianos vivenciadas por brasileirxs. A despeito da brutalidade dessas mortes e da responsabilidade institucional dos "representantes da 
segurança pública", a hashtag tornou-se possível mediante, essencialmente, a articulação de pessoas e grupos de militância negra na internet e para além dela, e também foi influenciada pelas coberturas midiáticas frente a esse trágico acontecimento.
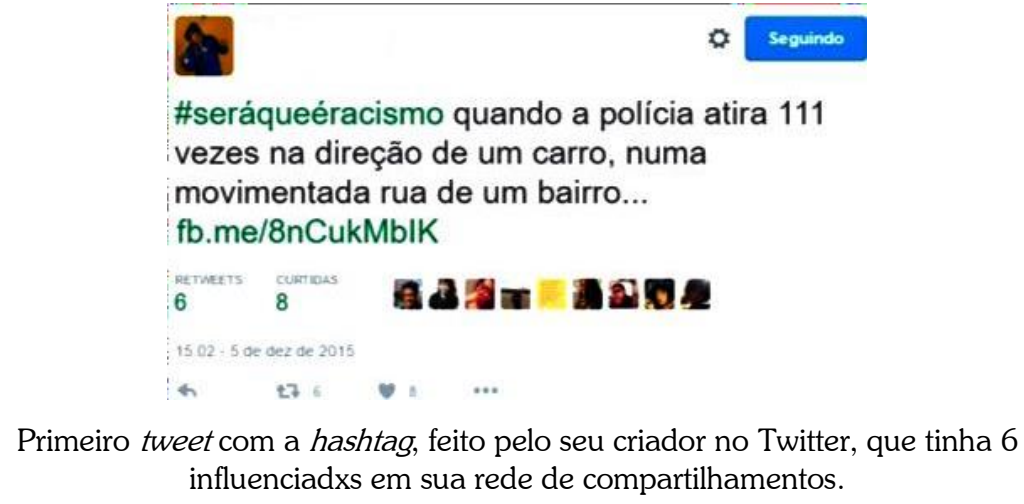

Airá é grafiteiro, tem 34 anos e superior incompleto. Reside no Rio de Janeiro e se autodeclara preto. A partir do seu relato, notam-se aspectos constitutivos da base da criação dessa hashtag atrelados a diversos processos de identificação do seu criador: observam-se a relação da criação da hashtag com um contexto de protesto off-line sobre a experiência de racismo de jovens executadxs por policiais; a relação com a experiência política do criador, que se considera "ativista político inclinado à esquerda"; a relação com a experiência profissional do criador (por ser artista, grafiteiro, inclinado à atuação nessas causas sociais, idealizou o termo como "um grito em um mural de rua", como ressaltou em entrevista); a relação com a sua experiência educacional (já foi estudante de publicidade e pensou na frase também como instrumento de conscientização de outras pessoas); a relação com as suas experiências de uso prévio de outras campanhas de hashtag, e com o caráter independente que envolveu a criação dessa hashtag ("não teve apoio financeiro"), o que ele considera envolver certa liberdade quanto à apropriação do seu uso ("o uso 
da \#seráqueéracismo está sujeito a diversas interpretações e reações de qualquer pessoa").

Pode-se observar que a relação entre as experiências de racismos vividas pelo próprio criador $e$ as experiências de racismos vividas pelxs outrxs está na base dessa campanha $-e$ isto também influenciou os sequentes modos de uso da hashtag (seja por tweets ou retweets).

Procurando entender como a hashtag atingiu o seu momento de auge e se tornou pauta midiática, foram observados as suas dinâmicas na plataforma e os relatos do seu criador.

$\mathrm{O}$ conceito amplo e heterogêneo em torno do termo "racismo" envolve uma composição entre diversos fatores. Este, portanto, não pode ser naturalizado e analisado como fenômeno homogêneo, nem mesmo no contexto dos seus usos na hashtag. Distintos atores sociais o utilizam de diferentes modos. Por exemplo, neste contexto, houve nuances na cobertura da imprensa, sendo que grande parte da mídia hegemônica brasileira classificou os adolescentes mortos apenas como jovens (sem evidenciar recortes de raça, sexo, classe social); além disso, muitas manifestações midiáticas não encararam o ocorrido como racismo, e sim como um equívoco policial, afirmação que também descontextualizou o fato do batalhão envolvido ser o mais mortal do Estado, atuando em uma área das mais pobres e negras da cidade. Os racismos, portanto, operam em sua complexidade de modo explícito e implícito, nas entrelinhas, em estereótipos muito estruturais da sociedade e das subjetividades brasileiras, onde diferentes sentidos são atribuídos por distintos atores sociais nas relações de poder entre xs envolvidxs.

\section{Na esteira de outras hashtags: 2015 o Ano das \#feministas}

As dinâmicas de utilização da \#seráqueéracismo foram muito influenciadas por outras hashtags que lhe antecederam nas mídias digitais $e$ que tiveram alto destaque nacional $e$ internacional, originadas no ano de 2015. Refere-se especialmente à \#primeiroassédio e à \#meuamigosecreto, mas também às 
campanhas \#SomostodosMaju e \#SomosTodosTaís, utilizadas como apoio aos episódios de racismos sofridos pelas duas personalidades. $\mathrm{O}$ contexto foi marcado nas redes sociais on-line brasileiras pelo uso intensivo de "hashtags feministas" direcionadas a relatos de machismos, racismos, assédios sexuais e outros tipos de violências contra as mulheres, ações integrantes do movimento intitulado por grande parte da mídia brasileira como "Primavera das Mulheres", que conferiram maior visibilidade a tais temáticas. Em menor escala de divulgação e participação nas mídias digitais do que essas, surgiu a \#seráqueéracismo, inicialmente no Twitter.

\section{Que influenciadorxs?}

O maior uso da \#seráqueéracismo ocorreu por meio de retweets (compartilhamentos de publicações de alguns/algumas influenciadorxs), que correspondem a $68 \%$ das postagens feitas; $e$ o menor, por meio de postagens de relatos e produção de conteúdos via tweets diretos feitos pelxs demais participantxs. Dessa forma, buscou-se compreender os motivos, intenções, percepções $e$ interesses dessxs influenciadorxs nos agenciamentos dessas narrativas.

Os perfis com as postagens mais retweetadas foram os seguintes: 


\section{Fábio Kabral @Ka_Bral}

a Dez2015

111 tiros. \#Seráqué́racis mo? "Quando o ódio dominar năo vai sobrar ninguém..." Https;ilt.colTKbod7mTvp

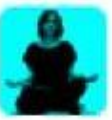

Carol Moreno Q Qanarina

6 Dez 2015

Pra quem viu a hashtag \#seraqueeracis mo e năo sabe do que se trata: https: t.co O6h1,155dry

\section{SNAP:LudimaraSouza $@$ LudimaraSouza}

6. Dez2015

Negro de dreads é sujo, branco de dreads é estiloso \#seraquéracis mo

\section{Think Olga ThinkOlga}

7 Dez2015

Histórias de racis mo estào sendo denunciadas com a has htag

\#seráquéracis mo. E pra ler, compartilhar e aprender! 


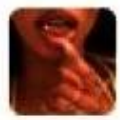

\section{PUFF PUFF @ixghettowomanx}

6) Dez 2015

quando uma negra usa turbantes eles chamam de macumbeira quando é uma branca... ah, claro, é FASHION \#seraqué́racis mo

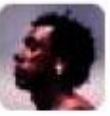

Fábio Kabral @Ka_Bral

8 Dez 2015

China 'esconde' ator negro de cartaz do novo filme Star Wars |

hitps://t.co/c.JroNE7tju \#SeráQueERacismo? https://t. coiZUxNBzXso3

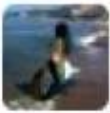

\section{SNAP:LudimaraSouza LudimaraSouza}

7 Dez 2015

Acha ok ter aulas de religiăo cristă, mas estudar a cultura e religiöes afro é cristofobia \#seraqueeracis mo?

\section{BR}

\section{BuzzFeed Brasil @BuzzFeedBrasil}

7 Dez 2015

Pesscas estăo usando a hashtag \#seraqueéracismo para falar de preconceito racial https:/it.co/FhwO0x0.A.p3 https://t.co/dihJ DJGzdR

\section{$\mathrm{E}$}

\section{pavê comunista @eatpussy}

a Dez 2015

\#seraqueeracis mo https://t.coig8GbOTSCCk

Perfis mais retweetados sobre a \#seráqueéracismo: dentre xs 10 influenciadorxs (incluindo as duas páginas institucionais que não participaram da pesquisa), 6 pessoas aceitaram conceder entrevista e participar do trabalho. Em sua maioria, jornalistas ou blogueirxs envolvidxs com essa temática. Duas pessoas não aceitaram participar da pesquisa.

Nesse contexto, observou-se a configuração de modelos de demandas de conteúdos sobre situações de racismos e modos de uso específicos em torno da hashtag (reprodução de modelos de 
postagens/conteúdos e de retweets, por parte da maioria dxs participantes), que foram muito pautados por tais influenciadorxs em relação às demais postagens.

Dessa forma, o Twitter não sustenta a difusão de todas as vozes em igualdade de condições: ele se autoproclama como serviço público neutro, mas fomenta uma estrutura hierárquica de alguns twitteiros com mais prestígio nessa rede social desigualdade que ocorre, em parte, pela "arquitetura" da plataforma, que confere privilégios a certxs participantes com alto potencial para aumentar o seu volume de tweets e aderir mais seguidores, e também pelas decisões ativas dxs próprixs participantes (Van Dijck, 2016).

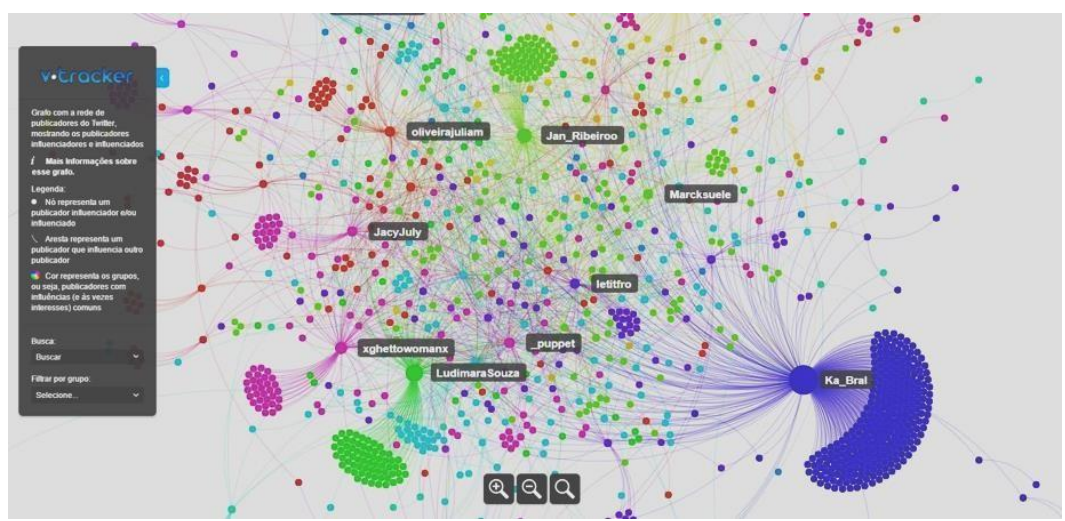

Grafos na plataforma V-tracker, com as redes de compartilhamento de retweets dxs influenciadorxs (Representado no maior nó em azul, o influenciador mais retweetado: 448 influenciadxs, mas não concedeu entrevista).

Após a entrevista, observa-se que o que move tais agentes a participarem dessa campanha são: os processos de identificação 
com temáticas voltadas à "militância feminista negra"3; a importância conferida a tais movimentos coletivos; as participações e experiências pessoais prévias dessas pessoas em outras campanhas de hashtags nas mídias digitais relacionadas; o desejo de contribuir, junto dos movimentos, com tais iniciativas, por experiência subjetiva e coletiva; a importância atribuída à visibilidade e ao alcance conferido por estas campanhas; e o efeito produzido por elas em outras mídias - que extrapolam as conexões restritas dxs que se organizam apenas em torno das mesmas redes sociais de conexões on-line. Mesmo considerando que tais ações não são suficientes para o combate aos racismos, já que essxs compreendem como sendo estrutural na sociedade, tais agenciamentos contribuem, na visão de todxs xs entrevistadxs, para uma prática antirracista.

Essxs influenciadorxs credenciam positividade ao uso da campanha frente ao público que se identifica com seus relatos. Segundo tais relatos, ser reconhecido socialmente (especialmente em relação às injustiças e sofrimentos cotidianos) e também obter certa posição social a partir da própria ação, voltada a essa causa que se objetiva combater, confere positivação valorativa, tanto em relação a si próprio quanto a outrxs que também sofrem pelo mesmo motivo. Para xs influenciadorxs, no geral, essa experiência social, midiática e subjetiva é um modo de resistir aos racismos estruturais na sociedade brasileira $e$ aos seus efeitos sobre as subjetividades dxs envolvidxs (já que, para elxs, a visibilidade conferida a essa temática pode provocar maior "conscientização e reconhecimento").

${ }^{3}$ Contexto que envolve uma intertextualidade entre as mídias: o que aparece no Twitter está relacionado, de algum modo, a diversos campos de discussão na internet (e fora dela), por distintos atores sociais e pelas militâncias e suas agendas/pautas. 


\section{Que experiências? quais racismos? \#experiênciasnegociadas}

O que xs participantxs apresentam como "experiências de racismos" vividas na atualidade, por meio dos relatos descritos abaixo, não foi tomado, a priori, como uma verdade ou evidência legitimadora e determinante da realidade social (Brah, 2006). Nesse sentido, buscou-se apreender, para além desses relatos, os conflitos, as necessidades e as normas emergentes, relacionandoos com alguns processos históricos e sociais correlatos.

Assim, o eixo analítico "experiências", em contraponto a um status de "experiência real inquestionável", está atrelado à narrativização sobre as identidades - entendidas aqui como processos de identificação, em seu aspecto discursivo, $e$ observadas nessas relações como locais de contestação, de exigências múltiplas e conflitantes (Scott, 1998).

Relato, a seguir, as principais demandas discursivas postadas como experiências sobre racismos, não no sentido de entendê-las como a origem do conhecimento e visão de umx sujeito individual (sujeito que revê a experiência e/ou a visão $\mathrm{dx}$ próprix pesquisadorx), correndo-se o risco de naturalizar ainda mais as diferenças, e sim visando apontar reflexões sobre como as diferenças operam (Scott, 1998), dentro do recorte proposto, nesses espaços de contestações políticas e subjetivas - e também de produção de conhecimento (em consonância com reflexões sociológicas sobre como certas normas podem ser constituídas, reproduzidas e modificas). 
\#seráqueéracismo abusos sexuais, estupro de meninas com até 14 anos, da comunidade Kalunga que vive em... fb.me/RmMvd8Iz
4 $\quad$ เ7 2
- 5
$\bullet$

- 6 de dez de 2015

te.

amigos, usem a hashtag \#seraqueéracismo para denunciar o racismo nosso

de cada fia
4 27
- 3
$\bullet$

\section{- 6 de dez de 2015}

\#seráqueéracismo quando você faz recorte de raça dentro d mov sociais e seus mgs ficam ofendidos $\mathrm{pq}$ acham $\mathrm{q}$ Td se resume em luta de classes?
h 2714
23

\section{6 de dez de 2015}

the ela ficava comigo escondida e de repente apareceu namorando uma branca \#seraqueéracismo

\section{ค 477 14 14 \\ 5 de dez de 2015}

\#seráqueéracismo quando te falam que você quase tomou um tiro de um segurança particular, por estar passando no... fb.me/UceFZT7w
4 47
C 4

5 de dez de 2015

\#seráqueéracismo quando a polícia atira 111 vezes na direção de um carro, numa movimentada rua de um bairro... fb.me/8nCukMblK
H
ᄂ7 6
8 
elas falaram que somos todas mulheres, e que mulher não oprime a outra...

mesmo a outra sendo negra e pobre

\#seraqueéracismo

4 27

○ 2

- 6 de dez de 2015

Pessoas brancas falam sobre pautas de pessoas negras só $\mathrm{p}$ ganhar destaque mas na vdd eles tão cagando \#seraqueéracismo

\section{2723 - 38 \\ 6 de dez de 2015}

quando resolvemos falar sobre a solidão da mulher negra, eles disseram que não existia isso, que tudo é questão de gosto \#seraqueéracismo
४
เ7 4
- 7

6 de dez de 2015

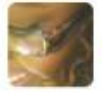

\#seráqueéracismo quando uma velinha branca passa por você na rua e diz: muito bonitinha, mas o cabelo...
4 $\quad$ เ 12
- 25
6 de dez de 2015

\#seráqueéracismo 5 pretos mortos c/ 111 tiros e nem $3 \%$ das redes sociais se comove pq preto injustiçado no $\mathrm{Br}$ ñ é digno da sua ft de perfil

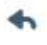
เ7 55
65 


\section{6 de dez de 2015}

\#seráqueéracismo quando entro em uma loja de roupas e além de ninguém vier me atender, ficam "olhando torto",... fb.me/4EIKYMGE7

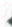

七7

- 2

6 de dez de 2015

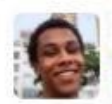

\#seraqueeracismo quando meu pai diz que black power deixa com aparência de sujo?
4 2717
14

@LudimaraSouza.6 de dez de 2015

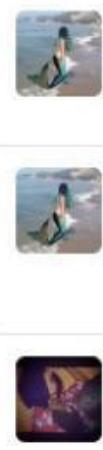

Negro de dreads é sujo, branco de dreads é estiloso \#seraqueéracismo

ค $27133 \bullet 103 \quad \cdots$

@LudimaraSouza.6 de dez de 2015

Acha que todo negro que entra na loja é pra roubar e não comprar

\#seraqueéracismo

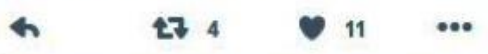

. 6 de dez de 2015

Chamou meu nariz de tomada e disse que meu cabelo é duro

\#seráqueéracismo
ค 278
12

\section{6 de dez de 2015}

ataca religiōes de matrizes africanas por fazerem sacrificios com animais, mas no seu natal não falta peru e pernil \#seraqueéracismo

Sintetização de tweets dos principais modos de uso da \#seráqueéracismo.

As expressões de afetividades coletivas de injustiça, indignação, sofrimento, perseguição, baixa auto-estima foram frequentemente imprimidas em tons denunciativos $e$ atreladas às "experiências sobre racismos" relatadas pelxs participantes. Essas demandas discursivas foram essencialmente pautadas por três eixos temáticos: 1) experiências relativas às características físicas (fenótipo), frequentemente relacionadas às estereotipações: cabelo, cor da pele, demais partes do corpo; 2) experiências relativas à falta de representantes negrxs em instituições: movimentos sociais/coletivos, mídias, restaurantes, hotéis, escolas/universidades, instituições religiosas; 3) experiências 
relativas às estereotipações $e$ naturalizações de gênero $e$ sexualidade ("racialização do sexo e sexualização da raça"). Tais visões cristalizadas, expressas nas discursividades, conferem certa posicionalidade sobre xs negrxs que, em sua maioria, utilizam a hashtag para confrontá-las e demonstrar ("viralizar") um sentimento de recusa atrelado a essa situação (a maioria vivenciada fora da internet, mas algumas situações ocorridas nas mídias digitais e também no próprio processo de uso da hashtag).

Essas foram, portanto, as principais associações temáticas observadas nos usos da hashtag, tanto nos relatos por parte de tweets diretos quanto de retweets, enfatizando uma experiência que passa direta ou indiretamente pelos sujeitos e subjetividades.

\section{\#Cabelo e \#Cordapele}

A maioria das discursividades decorreu dos relatos de situações de racismos direcionadas às pessoas negras (tendo ainda poucos relatos sobre indígenas, nordestinxs, haitianxs). A seguir, aponto as principais demandas associativas em relação às naturalizações fenotípicas: uso da \#seráqueéracismo para relatar a associação que as pessoas em geral fazem do cabelo de pessoas negras com a dureza e com a feiura; para relatar situações comparativas entre cabelos de negrxs, associados à sujeira e à mendicância/marginalidade, $e$ de brancxs, associados à beleza $e$ ao estilo (mesmo quando ambos usam os estilos dreadlock ou blackpower, por exemplo); para relatar como o cabelo é limitador de reconhecimento social $e$ da beleza negra por parte $\mathrm{dx}$ outrx (em geral brancxs, mas até mesmo de negrxs); para relatar situações em que o uso de adereço no cabelo dx negrx é visto como estigmatização religiosa - $e$ associá-lx a perigo.

Em relação aos relatos sobre cabelos e demais caracteres morfológicos, observou-se a seguinte demanda: quanto mais próximo ao referencial branco (cabelo liso, proporções corporais específicas), mais a pessoa é aceitável socialmente (na família, no trabalho, na escola, nas relações sociais de modo geral - sendo comum o preconceito até mesmo de familiares, negrxs e não- 
negrxs). A cor da pele também é diferenciada, assim como o tratamento social, em graus de tonalidade. Quanto mais próximo ao referencial de cor branca, mais há aceitação social. Alguns modos de sanções sociais relacionados à cor da pele foram frequentes nos relatos: piadas, dificuldades nas relações de trabalhos, nos relacionamentos amorosos, com preconceitos também de familiares negrxs e não-negrxs.

Ainda sobre caracteres morfológicos, foram frequentes as associações depreciativas à pessoa negra e desqualificação de seus traços corporais, comparando suas partes do corpo a objetos e a animais/não-humanos (associação de nariz à tomada; da pessoa com um animal/macaco) - vinculando, em contrapartida, beleza a formas corporais específicas atribuídas a corpos brancos.

Nessas discursividades analisadas, observou-se a utilização de estereótipos como descritores potentes e simplificadores, por meio de visões preconceituosas sobre aquele de quem se fala (Beleli, 2014).

Essa ação de inferiorização $\mathrm{dx}$ outrx e de sua experiência (processos de racialização) é parte de um processo de alienação colonial que interfere diretamente nas subjetividades $\mathrm{dxs}$ envolvidxs nesta dinâmica, sob o qual foi construída uma fobia em relação à pessoa negra (colocando-a como x outrx desumanizadx $e$ perigosx, também por meio de seus atributos e características físicas, vistos como "exagerados", que foram sendo mistificados $e$ animalizados pelx brancx - muitas vezes, interessadx em não associar tais características a si mesmx, ou seja, são características faltantes à pessoa branca) (Fanon, 2005).

A mulher negra ("mulata com nádegas grandes"4) e o homem negro ("viril, bem dotado") são hipersensualizados, e isso é uma estratégia de promover a "racialização do sexo" e a "sexualização da raça". Esse processo de racialização confere normalidade; trata-se de uma estratégia política de desumanização

\footnotetext{
"O termo "mulata" deriva de "mula" ou "mulo" e faz referência ao que é híbrido em relação ao cruzamento de espécies. Esta expressão pejorativa é usada desde o período colonial para designar pessoas negras de pele mais clara, filhas de mulheres escravizadas - e também estupradas - pelos senhores de engenho.
} 
$\mathrm{dx}$ outrx - que ocorre por meio da construção e da afirmação de estereótipos, dentro da produção de valores nacionais que normatizam $e$ hierarquizam as diferenças. Considerando as formulações de branqueamento do final do século XIX e seus discursos sobre mestiçagem brasileira, ainda há uma tendência em criar um espectro para classificar cores de pele (como no caso: "mas você nem é negra, é mulata/morena"), tendo o padrão branco como referencial de maior aceitação, o que tende a dissolver o binarismo negrx/brancx e consequentemente as identificações assumidas por tais pessoas (Miskolci, 2012).

Os relatos sobre estas "experiências sobre racismos" nos usos da hashtag apontam que a aparência define quem é ou não negrx e quem é ou não bonitx/inteligente - reatualizando também a pesquisa de Iara Beleli (2005), que demonstra que a cor é um dos fortes atributos de beleza no contexto da propaganda publicitária brasileira. Tais códigos, quando associados a um referencial nacional, conferem exotismo e sexualidade exacerbadxs à mulher brasileira (Beleli, 2005).

Entretanto, experiências coletivas não podem ser reduzidas à soma das experiências individuais, pois envolvem outros processos de significação que são singulares em torno de eixos específicos de diferenciação e subjetivação - sexualidade, gênero, racismo, classe social, entre outras variáveis. Brah (2006) pontua que, para se ter uma consciência expandida de construções de identidades em um certo contexto, é preciso parcialmente apagar $e$, ao mesmo tempo, carregar traços de outras identidades que sempre estão em processo (Brah, 2006: 371-372). Assim, "o sujeito pode ser efeito de discursos, práticas e instituições, mas ao mesmo tempo, ele está em processo, experimenta a si mesmo e se refaz em novas posições e investimentos que lhe atribuem significado" (Brah, 2006: 373).

\section{\#Instituições}

As demandas discursivas $e$ associações relacionadas a instituições apareceram da seguinte forma: uso da 
\#seráqueéracismo para relatar críticas sociais relacionadas à falta de representação de pessoas negras na mídia/internet, escolas/universidades; para relatar críticas sociais voltadas à condição de "rebaixamento serviçal" (com desrespeitos nesta relação de poder hierárquica), em que $\mathrm{x}$ negrx é sempre empregadx e x brancx patrão (como nos relatos de situações de racismos em restaurantes, hotéis, residências); para apontar críticas à associação dx negrx à intenção de furto, ao assalto, ao perigo, à pobreza, feitas em diversos espaços, públicos e privados (ruas, lojas, shoppings). Foram muito frequentes narrativas sobre abordagens policiais envolvendo constrangimentos $e$ fortes ameaças feitas às pessoas negras (situações de armas apontadas, sirenes, trocas de tiros, homicídios, violência policial a partir de episódios em que pessoas negras são "confundidas", tomadas como assaltantes). Neste caso, x negrx é colocadx, de antemão, na condição de "perigoso" - por parte de certas autoridades. Houve usos também para relatar críticas a participantes/ativistas, pertencentes a diversos movimentos e coletivos, no sentido de que a questão racial, também nesses espaços, frequentemente é pauta menor em relação às outras ("depois de não ver as feministas badaladas darem retweet em massa na \#seráqueéracismo, entendi de uma vez o que já sabia, feminismo é branco e ponto" alertando para a falta de apoio dos próprios movimentos feministas engajados nestas campanhas ao recorte racial). Nessa hashtag também foi comum o uso de termos presentes nas agendas destes movimentos/coletivos ("empoderamento", "lugar de fala", "racismo reverso", entre outros).

A \#seráqueéracismo também foi muito usada para criticar uma associação direta e linear feita entre pessoas negras integrantes de religiões de matriz africana ao perigo, à demonização, perversão ou problema, em contraponto às feitas com base em outras religiões (em especial as de origem cristã). Também foi utilizada para relatar críticas às práticas racistas na internet (no próprio uso desta hashtag feito por outrxs participantes); para conferir apoio midiático a outros links/matérias com temáticas associadas ao racismo, também por parte da mídia 
(estas entidades, em geral, utilizam o momento de pico da hashtag para divulgar suas próprias matérias, tendo esta tendência de assunto como pauta); para divulgar a própria hashtag (com conteúdo informacional sobre a causa). Também foi frequente o uso de hashtags associadas nas postagens (criadas ou já existentes, como as de outras campanhas ou tendências do momento); para relatar críticas sociais sobre a baixa repercussão dessa hashtag, quando comparada às demais campanhas; e para relatar identificação com experiências de racismos relatadas por meio de hashtag ("tava lendo os tweets da tage quanta coisa eu já vi e aconteceu comigo").

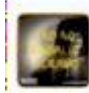

$$
\text { 2- Seguir }
$$

\section{Me disseram que eu não podia ser Paquita. \#SeráQueÉRacismo?}

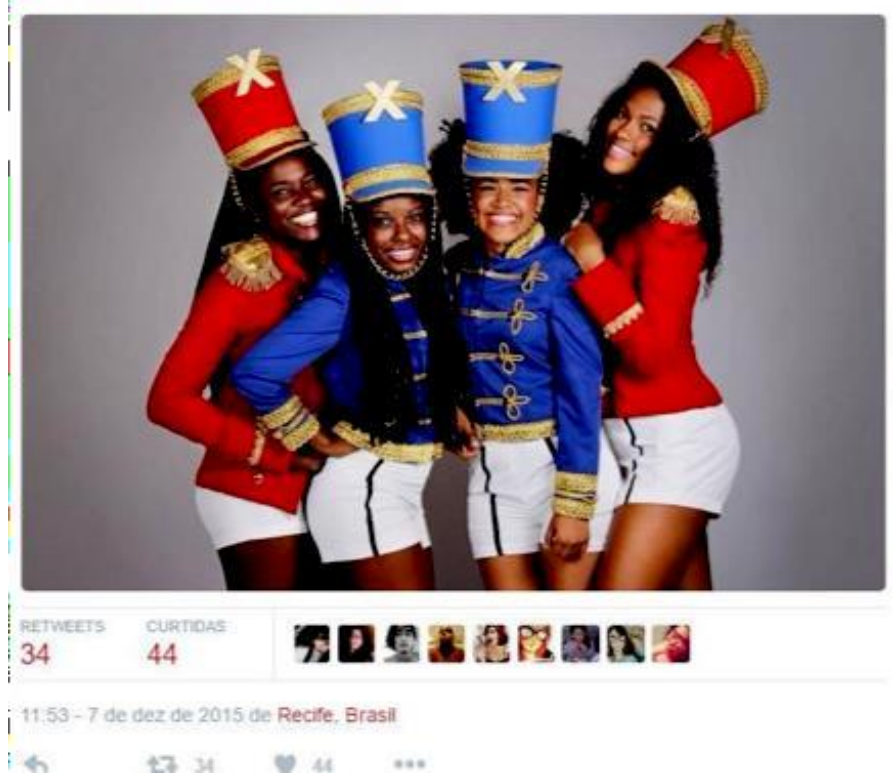

Tweet de influenciadora com 364 retweets e 165 influenciadxs 


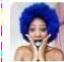

2- Seguir

Quando vc usa a hashtag \#SeráQueéRacismo e vem gente dizendo que vc ta exagerando, \#SeráQueéRacismo ?

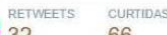

32

66

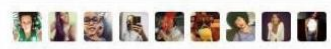

$23: 51-6$ de dez de 2015

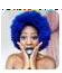

2- 2eguir

\#SeráQueéRacismo Quando dizem: Fulana é tão inteligente, pena que é negra.

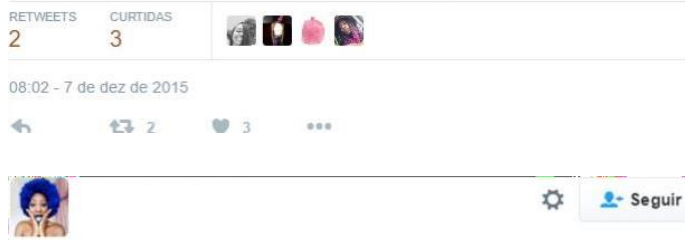

Você não é negra, é morena.

\#SeráQueéracismo

RETWEETS CURTIDAS

3

4

20보요

07.53- 7 de dez de 2015

Tweets de influenciadora com 112 retweets e 61 influenciadxs

Racialização do sexo e sexualização da raça \#diferençasnegociadas

Estes relatos de situações elencadas como "experiências de racismos concretas", que diferenciam os sujeitos por gêneros, raças, classes sociais, sexualidades (articuladas como fatores de distinção social), estimulam ainda a reflexão sobre o que é colocado em evidência e o que não é, sendo necessário examinar tais tensões colocadas entre "negrxs" $e$ "brancxs", feminilidades e 
masculinidades, sexualidades percebidas como "anormais" $e$ "normais".

Em relação aos aspectos de gêneros e sexualidades, a \#seráqueéracismo foi muito utilizada para criticar as seguintes relações direcionadas às pessoas negras: frequentes associações do homem negro a um pênis grande (vinculado aos termos "bem dotado", "pega de jeito", "negão"), da mulher negra à hipersexualidade, ao sexo sem compromisso/casual e a traços corporais estereotipados como seios e nádegas grandes (vinculadas a palavras como "gostosa", "bunda em pé", "ter um rabão" e ao "obrigatório gosto pelo samba"), em contraponto à mulher branca, frequentemente associada à beleza $e$ ao relacionamento sério, ao namoro (também em casos de relacionamentos entre mulheres e em casos em que o homem "diz ser adepto ao poliamor, mas só assume prelacionamentos com mulheres brancas", como afirmou uma entrevistada). Muitos relatos criticaram o recorrente uso da palavra "mulata" para se dirigir a uma mulher negra.

Foram frequentes os relatos de mulheres sobre a questão da "solidão da mulher negra", no sentido de esta não ser considerada verídica. Houve críticas a mulheres que não percebem a opressão que praticam com outras mulheres e descontextualizam essas outras vivências e situações de opressão.

O branco está convencido de que o negro é um animal; se não for o comprimento do pênis, é a potência sexual que o impressiona. Ele tem necessidade de se defender deste "diferente", isto é, de caracterizar o Outro. O Outro será o suporte de suas preocupações e de seus desejos (Fanon, 2005:147).

Estas discursividades evocam construções de gêneros, sexualidades e raças associadas a certa ideia de nacionalidade. Nesse sentido, a "mulata", muito associada a um objeto de desejo em diversas produções culturais, a "mestiçagem" e a sedução são elementos muito marcantes no imaginário brasileiro - dentro $e$ 
fora do país. Dessa forma, as narrativas históricas embasam a atualização desse imaginário de um Brasil muito marcado pela sensualidade da mulher brasileira (sendo que a hipersexualização aparece como fator atenuante do estranhamento dessxs que são marcadxs pela cor) (Beleli, 2005).

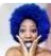

$$
2 \text { 2-Seguir }
$$

Dizer que as negras são boas de cama e dão um bom caldo só prq são negras, mas pra namorar não servem? \#seraqueeracismo

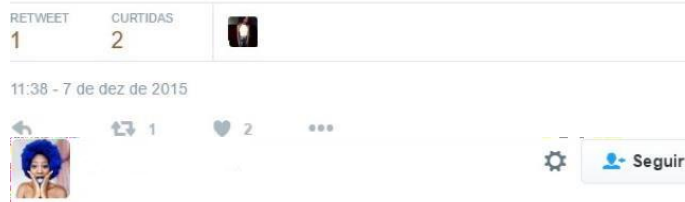

\#SeráQueéRacismo Quando dizem: Fulana é tão inteligente, pena que é negra.

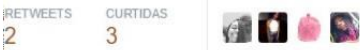

08.02 - 7 de dez de 2015

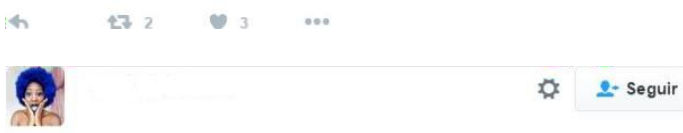

Você não é negra, é morena.

\#SeráQueéracismo

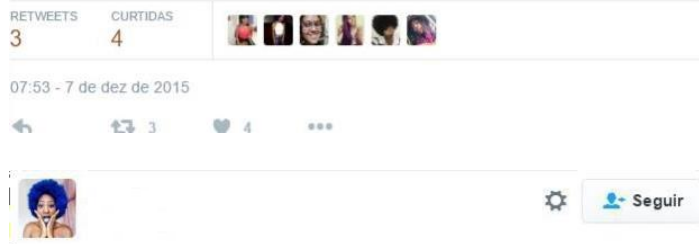

Quando ficam indignados por você ser negra e não saber sambar. \#seraqueeracismo

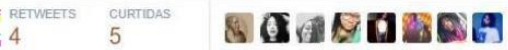

13:10 - 7 de dez de 2015

4 $\quad$ t? 4 
Tweets de influenciadora com 112 retweets e 61 influenciadxs

A Teoria Queer e os Estudos Pós-Coloniais convergem para a compreensão de que modos de opressão que envolvem clivagens como raça e sexualidade estão vinculados ao mesmo processo de racialização do sexo e de sexualização da raça, o que desencadeia a criação de outras clivagens essencializadas socialmente como nação (Brah, 2006). Assim, a matriz essencializadora e subalternizante presente na conexão raçasexualidade são pertencentes a um mesmo processo normalizador que cria seres como abjetos ou menos humanos (Miskolci, 2009).

Nessa perspectiva, é necessário considerar que o processo de formação nacional brasileiro foi pautado em uma lógica de racialização hierarquizada desde a colonização; e tal hierarquia, simbólica e material, teve como referência o ideal de branquitude europeu (tanto no quesito fenotípico quanto nos valores, discursos e práticas). Tais fatores repercutiram não só no plano físico dos corpos, mas também no subjetivo e histórico-social, neste processo de desenvolvimento enquanto nação. Ou seja, a harmonia da sociedade sob a qual a elite brasileira pautou o seu projeto político e o seu desejo de nação foi baseada em uma realidade biológica embranquecedora. $\mathrm{O}$ discurso de um projeto político racializante englobava também o controle da sexualidade e do gênero do povo, que se deu por meio de práticas discriminatórias, disciplinarizadoras das relações íntimas/sexuais e orientadoras a um padrão social reprodutivo, masculino, branco, heterossexual, viril, elitista, que configuraram uma heterossexualidade compulsória à brasileira (Miskolci, 2012).

O discurso nacional de propagação da mestiçagem também serviu como uma boa desculpa de que a sociedade brasileira não era racista, passando a afirmar-se como o país miscigenado do samba, da dança, das mulatas, e configurando-se, portanto, como não racista (demandas muito comuns nos relatos de experiências em torno dessa hashtag). O racismo, então, foi propagado enquanto algo externo à cultura brasileira, considerando a mestiçagem como um fator positivo contra o seu próprio racismo. 
Em síntese, a superação do colonialismo no Brasil não correspondeu à superação das colonialidades (Miskolci, 2012).

Racismos são contingentes, contextuais e possuem várias origens históricas; articulam-se às clivagens de classe social, gênero, sexualidade, entre outras, de modos específicos em condições sociais e históricas distintas (Brah, 2006).

Então, ao considerar as diferenças de sexo, gênero, raça $e$ sexualidade nas experiências relatadas, observamos as distinções feitas como formas de categorização de pessoas. Como aponta Beleli (2005), a evocação dessas diferenças informa condutas e procedimentos a partir de uma norma presumida, indicando como esses diferentes corpos se movimentam na sociedade; ao mesmo tempo, informa também um modo de ser nacional. Para além dos aspectos fenotípicos, observamos que as construções de gênero $e$ sexualidade são atravessadas por elementos morais, pelos tensionamentos entre masculinidades e feminilidades, cores claras e escuras, como descritores da realidade existente. Mas que, de forma ambivalente, ora reiteram, ora desafiam normas vigentes.

Butler (2014) acrescenta que regulações constroem regularidades, e são modos de disciplinarização, formas modernas de poder que operam por meio de normas. Estas produzem efeitos e operam sobre o nível de práticas sociais, dentro do padrão implícito da normalização (o que, nos discursos, remete à produção de sujeitos) - ou seja, este campo de realidade é produzido também por normas de gênero e sexualidade. Então, oposições à norma estão contidas dentro da própria norma, e esta é, portanto, uma forma de ação contingente (Butler, 2014). Assim, discursividades normalizadoras das diferenças produzem sujeitos, mas também os constitui ativamente.

Nessa perspectiva voltada aos usos da hashtag aqui abordada, os processos de normalização estão em ação por parte dessxs participantes que percebem uma estrutura impositora sobre si: os racismos que, na maioria dxs relatos, são atribuídos aos brancxs - posicionalidade de sujeito também muito cristalizada pela maioria dxs participantes - apesar de também serem atribuídos às próprias pessoas negras, em alguns casos. Dessa 
forma, xs que experienciam os racismos se organizam $e$ se identificam orientados à sua resistência.

Hall (2005) compreende identidade como um processo contínuo e descentrado de identificações dos sujeitos de acordo com as suas experiências culturalmente acessadas pelas relações sociais, e não como conceito rígido que delimita estereótipos de (a)normalidades, pois esse último realça as hierarquias sobre as diferenças por parte dos hegemonicamente estabelecidos como normais (Hall, 2005:129; Scott, 1995:24-25).

Hall (2005) aponta ainda que é na dinâmica e na complexidade das relações sociais que envolvem os sujeitos que tal posicionamento se processa e se diferencia - sendo que as próprias posicionalidades desses sujeitos estão sendo formadas na experiência processual que envolve as mídias digitais.

Identificação e diferenciação são, portanto, processos simultâneos que constituem esses usos da hashtag. As identidades, compreendidas como processos de identificação, são caracterizadas pela multiplicidade relacional e mutável de posições que constituem os sujeitos diante de circunstâncias pessoais, sociais e históricas (Brah, 2006).

Portanto, por um lado, são reiteradas normalizações das diferenças (na utilização de estereótipos e visões preconceituosas sobre $\mathrm{x}$ negrx e nas diversas ações elencadas de inferiorização $\mathrm{dx}$ negrx e de sua experiência. Também foram muito frequentes os apontamentos de que xs brancxs só se aproveitam de temáticas antirracistas para se autopromoverem, e que não estão de fato interessadxs em mudar seus comportamentos racistas) - situações que também naturalizam o binarismo brancxs x negrxs, por meio do qual a posicionalidade de "sujeito brancx" também é fixada (muitxs participantxs pediram para que brancxs não utilizassem a hashtag seráqueéracismo: "brancxs, não usem a \#seráqueéracismo"; "um debate sobre negrxs com a maioria branca falando"; "brancos se incomodando com nossas declarações sobre racismo que sofremos no dia a dia"). Este argumento também foi muito pautado e endossado por outros processos de normalizações, no uso dessa hashtag, também por 
parte dxs que relatam sofrer racismo por serem brancxs e estarem em situações em que se sentem discriminadxs por negrxs (apesar de terem sido casos raros, demonstra a descontextualização social/subjetiva e a redução de uma problemática nacional muito complexa à inversão de valores em torno da temática e das experiências/vivências, o que contribui para reproduções acentuadas de racismos e processos de diferenciação social).

Por outro lado, alguns modos de uso também desafiam normas vigentes e produzem certos deslocamentos, mesmo dentro dos jogos de ambivalências destacados - os usos da hashtag são muito pautados por certa prática contestatória de uma percepção de norma vigente racista, que transita nesse jogo contraditório (há, por exemplo, relatos críticos no sentido de que algumas pessoas usam a hashtag para descrever sua situação de opressão $e$ acabam oprimindo outras diferenças, ou seja, muitas vezes reforçando situações racistas e/ou sexistas, entre outras).

\section{Apontamentos finais}

A hashtag pode ser compreendida como um modo de comunicação sobre si mesmo e de textualização de subjetivações, muito marcada por processos de identificação e modos de uso voltados a narrativas sobre afetos, experiências e questões relacionadas às diferenças sociais.

A ideia de experiência remete a uma zona conflitiva nesses usos da hashtag (experiências de racismos são contextuais $e$ contingentes), sob a qual diferentes ideias e afetos convivem nesta alta proliferação de conteúdos, que envolve ideias com maior ou menor grau de normatização das diferenças - considerando inclusive narrativas com inclinações "antifeministas" $e$ "antirracistas". Nesse sentido, o convívio de experiências parecidas, mas que levam a leituras distintas, ora reproduzem "subalternizações", ora não possuem fixidez a certas pautas de movimentos sociais até mesmo antirracistas, por exemplo, porque alguns desses sujeitos podem não se identificar com certo lugar de 
"subalternização" - enfoque que ultrapassa a abordagem desta pesquisa.

Um dos usos mais frequentes foi a demarcação de certas posicionalidades de sujeitos (tanto de "brancxs" inferiorizando "negrxs", quanto no posicionamento destxs em relação aos "brancxs", que também são frequentemente cristalizados nessas relações por serem o outrx racista, na maioria dos casos). Nesses usos, indica-se posições mais ou menos positivadas de "homens", "mulheres", "brancxs", "negrxs".

Aliado ao uso densamente emocional observado nestas narrativas, nota-se que o relato do racismo dx outrx consitui-se em um modo de uso muito frequente - que está diretamente vinculado ao potente desejo (de reconhecimento social e afetivo) que rege este uso. Este reconhecimento, que muitas vezes é negado ao negrx até mesmo no próprio processo de uso das mídias digitais é um elemento que contribui para que tais sujeitxs "sejam realocadxs negativamente em posicionalidades cristalizadas", o que mantém vigente uma neurose $\mathrm{dx}$ racismo voltada à responsabilização $\mathrm{dx}$ negrx.

Esses usos também dão visibilidade às "marcações negativas" sobre as diferenças - denunciam como a sociedade, em geral, demarca posições de sujeitos (essas demandas de experiências de racismos reforçam estereotipações $e$ normalizações - comparações com objetos e animais, por meio de cristalizações fenotípicas, a partir das quais xs brancxs, na maioria dos casos relatados, demarcam a cor da pele escura $\mathrm{dx}$ outrx como distante da sua posição); porém, muitas vezes, relacionam a hiperssexualização às negras como modo de amenização do "estranhamento" desses corpos marcados pela cor.

Para além dos significados atribuídos ao termo "racismo", no uso majoritário dessa hashtag, há um sentido predominante, apesar de haver exceções, que consiste nas imbricações entre: experiências que envolvem situações de violências simbólicas e/ou físicas e que causam sofrimentos, processos de inferiorização das experiências dxs negrxs e processos de desumanização conferidos a elxs sob a tônica nas questões corporais fenotípicas (cor da pele, 
cabelo, traços corporais), que atuam como distintivos desqualificadores sociais.

Tais discussões foram muito pautadas por um jogo conflitivo: de um lado, alguns que denunciam as práticas racistas $\mathrm{dx}$ outrx e da sociedade/instituições, de modo geral, com um sentido de combate a tais injustiças sociais e racismos - usos também muito marcados por uma demanda de reconhecimento social e afetivo deste sofrimento psíquico dxs que se posicionam como negrxs que experienciam essas vivências e que usam a hashtag para fazerem tais denúncias; de outro, também aparece uma desconfiança sobre a veracidade de algumas dessas experiências relatadas, alegando serem vitimismo $\mathrm{dx}$ negrx. Binarismos e leituras na chave opositora negrxs versus brancxs, com distintos modos de reprodução de estereótipos $e$ hierarquizações, foram preponderantes nos usos e nas denúncias de violências sofridas, embasadas em fenótipos/cor da pele na maioria das experiências relatadas. No entanto, embora minoritariamente no uso dessa hashtag, houve manifestações de pessoas que se apresentaram como brancas $e$ vítimas de racismos em algumas situações em que não se sentiram representadas ou respeitadas, especialmente em grupos formados majoritariamente por pessoas negras - o que endossa a heterogeneidade dos usos e sentidos atribuídos ao termo "racismo" - até como operador de não reconhecimento desta problemática social, das experiências e complexidades envolvidas, contribuindo para a reprodução de naturalizações, hierarquizações e desigualdades sociais (também nesses modos de uso da hashtag).

O passe-repasse da responsabilização ( $\mathrm{dx}$ outrx racista): entre a "experiência de racismo relatada" e a "contestação da própria experiência"

As postagens retweetadas permitiram analisar certo padrão nas discursividades (tanto nas replicadas quanto em algumas diretas - já que os modos de uso e o próprio conteúdo temático 
dessas postagens dxs influenciadorxs também afetaram grande parte das outras, feitas pelxs demais participantes).

Nesses usos da hashtag, observou-se que o falar diretamente sobre a própria experiência de racismo inclui, necessariamente, a responsabilização $\mathrm{dx}$ outrx (não identificado pelo nome, mas por certa posição social e/ou fenotípica, na maior parte dos relatos), como o modo de uso mais frequente. Ou seja, há um uso muito recorrente de narrativas marcadas por tons de denúncia à condição que $\mathrm{x}$ narradorx considera como prática racista $\mathrm{dx}$ outrx sujeito e/ou da sociedade/instituições sociais (e tais relatos são muito enfatizados e reiterados por termos afetivos: sofrimento, raiva, ódio, julgamento, tristeza).

Desse modo, a utilização da hashtag para falar e conferir visibilidade a essas vivências é fortemente marcada por um jogo conflituoso entre "a experiência de racismo relatada" (que envolve a percepção dxs participantes) e a "contestação $\mathrm{dx}$ outrx sobre a veracidade destas experiências". Dessa forma, a responsabilidade do racismo continua sendo centrada nxs negrxs, como estratégia de silenciamento e manutenção de uma neurose direcionada à própria negritude (Fanon, 2005), o que gera um uso da hashtag voltado a esse debate conflituoso das subjetividades envolvidas potencializando sentimentos de revolta, injustiça $e$ raiva por parte $\mathrm{dxs}$ negrxs que expressam as situações de racismos vivenciadas $e$ que recebem essas contestações. Nesse jogo de transferência da responsabilização sobre o racismo, este não é absorvido enquanto problemática da sociedade, de modo geral, $e$ as questóes relacionadas à branquitude continuam não sendo abordadas nesses processos.

É preciso, portanto, problematizar a questão do racismo ser pensado apenas em relação às pessoas negras, para compreender que todxs xs sujeitos experimentam seus gêneros, classes sociais $e$ sexualidades por meio da raça, mas que, neste processo, a "racialização da subjetividade branca não se torna evidente para os grupos brancos por já serem um significante de dominância" (Brah, 2006:345). Em outras palavras, a construção dx negrx, neste processo de racialização, é feita pelx brancx. A branquitude 
torna-se identificada com o humano, e a negritude, com o não humano, fatores que provocam efeitos devastadores nas subjetividades dxs envolvidxs (Fanon, 2005). Segundo Fanon (2005), este status de superioridade $\mathrm{dx}$ brancx, advindo do colonialismo, também lhe ocasiona uma alienação de sua humanidade e uma neurose em torno das suas subjetividades, que lhe fazem transferir atributos de inferiorização indesejáveis à pessoa negra, sob consequente autonegação dos mesmos. Dessa forma, xs "brancxs" e xs "negrxs" vivenciam a negação da sua humanidade, cada qual de um modo.

Então, a negação da existência do racismo no Brasil, especialmente por parte de brancxs (tanto dxs que se colocam dessa forma quanto $\mathrm{dxs}$ que cristalizam esse tipo de posicionalidade $\mathrm{dx}$ outrx) foi uma demanda muito expressa que também acentuou a dicotomia entre negrxs e brancxs dentro desses relatos. Tais fatores colaboram para a naturalização do racismo enquanto algo originado $e$ inventado pelxs próprixs negrxs, e também como problemática de responsabilidade delxs (endossados por relatos de que muitas experiências narradas eram vitimismo, além de outros que enfatizavam até mesmo que racismo não existe).

Estxs, em contraponto, retransferem a responsabilização do racismo à pessoa branca como $\mathrm{x}$ outrx que lhe conferiu tal neurose e tal posicionalidade de sujeito, também reforçando a cristalização dxs brancxs como "opressores" - nos usos dessa hashtag não foram encontradas outras proposições em relação a saídas das relações binárias citadas, especialmente entre "opressor $\mathrm{x}$ oprimido" e "brancx x negrx".

Esta contestação dos "racismos" relatados também foi favorecida pelo próprio caráter ambíguo traduzido pelo termo "será" (presente na tag \#seráqueéracismo), que abriu a possibilidade para distintos usos da hashtag (entre eles, os de contestação sobre a veracidade de certas experiências relatadas) intuito anunciado pelo próprio criador do termo: "ele remete não só a um tom irônico e provocador direcionado a uma sociedade brasileira muito marcada por racismos, mas principalmente à 
abertura de um questionamento sobre a possibilidade dos relatos produzidos com a hashtag serem ou não considerados racismos, $e$ esta decisão ficar sob a interpretação dxs leitorxs - ideia pensada com o intuito de não evidenciar um vitimismo por parte de quem os produz, e sim de dar abertura para diferentes interpretações a respeito das experiências narradas", relatou.

Em resumo, existiram distintos modos de uso da hashtag que atraíram e conferiram ainda mais nuances e visibilidades aos relatos: irônico, explícito - utilizando-se aspas como uma citação direta recebida, sendo questionador, apontando o racismo $\mathrm{dx}$ outrx, seja em tons mais informativos, denunciativos e/ou combativos; ressaltando as violências físicas e simbólicas em questão, ou em tons afetivos ressaltando tristezas, sofrimentos $e$ processos de identificações que emergiram nas discussões.

Essas fissuras e confrontos que a hashtag possibilitou dissipar, sob a formação de redes de concordância $e$ de discordância, contribuíram para a produção de modos de identificação e outros modos de uso da própria hashtag. desde manifestações híbridas de identificações por meio de demonstração de insatisfação perante "os racismos explicitados" até manifestações híbridas de identificações a partir de contestação de que "o racismo" exista de fato e o questionamento de que "tais experiências elencadas seriam de fato racistas".

Raça não é algo biológico ou essencializador e nunca foi um termo neutro no Brasil. Discuti-la pode ser considerado um tabu, pois essa condição aparece de forma estabilizada: "é como se as posições sociais desiguais fossem desígnio da natureza a atitudes racistas, minoritárias e excepcionais" (Schwarcz, 2012:30). Ao dizer que há uma harmonia racial, os conflitos são alocados no plano pessoal. Isso faz parte de um projeto amplo de naturalização das diferenças produzido pelos saberes ocidentais desde o século XIX (Schwarcz, 2012).

Então, falar de racismo aberta e explicitamente, na primeira pessoa, é uma limitação que ainda ecoa desse pensamento também manifestada nos modos de uso dessa hashtag. Esta prática do relato de experiências pessoais diretas não foi a mais 
recorrente, já que a maioria das publicações ocorreram via retweets. E, nesse sentido, narrar a própria experiência de racismo passa, necessariamente, também pela experiência relacional com x outrx racista.

Por meio de relações complexas e distorcidas, os modos de uso nas mídias digitais operam na construção de processos de identificação que envolvem tensões e desafios, aqui relacionados à ideia de eco proposta por Scott (2002), que se refere à produção de repetições daquilo que vem antes, multiplicando cópias e prolongando o som - identidades sendo mobilizadas como reprodução. Em consonância, os ecos são reproduções incompletas que oferecem de volta somente os fragmentos finais de uma frase (Scott, 2002).

Portanto, compreendemos que a internet produz ecos e fragmenta discursividades (há uma perda de controle e uma descontextualização sobre as motivações $e$ os objetivos da campanha - mesmo que a hashtag mantenha certa homogeneização nos seus modos de uso via retweets de influenciadorxs, há outros usos e debates que vão surgindo $e$ sendo reproduzidos que adquirem um movimento próprio durante o processo de uso da hashtag). Alguns aspectos associados à velocidade das tecnologias, às características da plataforma (restrição de número de caracteres), à transparência e à falta de controle sobre os resultados que a campanha vai obtendo também contribuem para tais reproduções desfragmentadas do próprio contexto inicial da campanha (Scott, 2002). Assim, estas discursividades, densamente marcadas por elementos afetivos, contagiam tais participantes de distintas formas.

As experiências revelaram conflitos entre valores, normas $e$ afetos compartilhados nesse espaço relacional. Nos usos da hashtag, convivem discursos que podem ser, de certa forma, contestadores e também autoritários em relação às diferenças. Há usos mais atentos ao "racismo dx outrx", outros muito pouco atentos às próprias atitudes normalizadoras das diferenças; há usos voltados à inferiorização das experiências relatadas como racismos, assim como há usos que permitem a abertura e a 
ampliação do debate em diversas plataformas e sob diversos graus de aprofundamento dessas questões sociais.

Analisar os processos pelos quais as identidades são construídas, isto é, por meio da linguagem e do discurso (sendo que raças, gêneros, sexualidades, classes sociais são efeitos e não causas de discursos, práticas e instituições) é também desvelar modos como xs sujeitos vão se efetuando nestes contextos em que identidades generificadas, racializadas e sexuadas também são performativas (Butler, 2008). Então, os sujeitos processuais colocam em cena as suas identidades envolvidas nos palcos metafóricos de sua escolha. Gêneros, raças, sexualidades e desejos são fazeres, constructos discursivos, e não há relação linear $e$ naturalizante entre eles.

No sentido de desnaturalizar e deslocar identidades, Butler (2008) assume que identidades são políticas, enquanto construções e desconstruções necessárias à agência, e estas subversões ocorrem nos discursos, na emergência de sujeitos nos discursos. Identidades são, portanto, resultados de relações de oposições, e também são possibilidades de produção de agência $e$ subversão, ou seja, os sujeitos são construídos nessas oposições. No entanto, para todo poder há, ao mesmo tempo, uma resistência. A relação entre sujeito e poder é, portanto, ambivalente (Butler, 2008). As identidades são produzidas também por meio do repúdio, da culpa, da perda (e os sujeitos também incorporam esses termos ofensivos de muitas formas) nas estruturas de poder onde ocorrem as formações dos sujeitos - que são passíveis de transformações. Então, há um potencial subversivo nos agenciamentos, por meio de operações subjetivas $e$ de psique que podem desafiar as leis $e$ as relações de/entre poderes e desejos (Butler, 2008).

\section{Referências bibliográficas}

Adelman, Miriam; Franco, César Bueno; PIRES, Andressa Fontana. Ruralidades atravessadas: jovens do meio campeiro e narrativas sobre o Eu e o(s) Outro(s) nas redes sociais. cadernos pagu, n. 44, Núcleo 
de Estudos de Gênero-Pagu/Unicamp, Campinas-SP, 2015, pp. 141170 .

Beleli, Iara. Amores online. In: Pelúcio, Larissa; SOUZA, Luís A. F.; MAGALHÃES, Bóris R.; SABATINE, Thiago T. (Orgs.). Olhares plurais para o cotidiano: gênero, sexualidade e mídia. Marília-SP, Oficina Universitária/Cultura Acadêmica, 2012.

BELELI, Iara. Gênero na mídia. In: MISKOLCI, Richard (Org.). Marcas da diferença no ensino escolar. São Carlos-SP, EdUFSCar, 2014.

BELELI, Iara. Marcas da diferença na propaganda brasileira. Tese (Doutorado em Ciências Sociais). Instituto de Filosofia e Ciências Humanas, Universidade Estadual de Campinas, Campinas, 2005.

BELELI, Iara. O imperativo das imagens: construção de afinidades nas mídias digitais. cadernos pagu, n. 44, Núcleo de Estudos de GêneroPagu/Unicamp, Campinas-SP, 2015, pp. 91-114.

BRAH, Avtar. Diferença, Diversidade, Diferenciação. cadernos pagu, n. 26, Núcleo de Estudos de Gênero-Pagu/Unicamp, Campinas-SP, 2006, pp. 329-376.

BUTLER, Judith. Regulações de gênero. cadernos pagu, n. 42, Núcleo de Estudos de Gênero-Pagu/Unicamp, Campinas-SP, jan./jun., 2014, pp. 249-274.

FANON, Frantz. Os condenados da terra. Juiz de Fora-MG, Ed. UFJF, 2005.

HALL, Stuart. A identidade cultural na pós-modernidade. Rio de Janeiro, DP\&A, 2005.

HALl, Stuart. Estudos Culturais: Dois Paradigmas. In: Da diáspora: identidades e mediações culturais. Belo Horizonte, Editora UFMG, 2009.

MISKOLCI, Richard. A Teoria Queer e a Sociologia: o desafio de uma analítica da normalização. Sociologias, n. 21, PPGS-UFRGS, Porto Alegre-RS, 2009.

MISKOLCI, Richard. Novas conexões: notas teórico-metodológicas para pesquisas sobre o uso de mídias digitais. Cronos, Revista da Pós Graduação em Ciências Sociais, vol. 12, n. 2, UFRN, Natal, jul./dez., 2011, pp. 9-22. 
MISKOLCI, Richard. O desejo da nação: masculinidade e branquitude no Brasil de fins do XIX. São Paulo, Annablume, 2012.

MoUTINHO, Laura. Diferenças e desigualdades negociadas: raça, sexualidade e gênero em produções acadêmicas recentes. cadernos pagu, n. 42, Núcleo de Estudos de Gênero-Pagu/Unicamp, Campinas-SP, 2014, pp. 201-248.

RECUERO, Raquel; ZAGO, Gabriela. Em busca das "redes que importam": redes sociais e capital social no Twitter. Anais da Compós 2009. Belo Horizonte - MG, 2009.

SANTAELLA, L.; LEMOS, R. Redes sociais digitais: a cognição conectiva do Twitter. São Paulo, Paulus Editora, 2010.

SCHWARCZ, Lilia Moritz. Nem preto nem branco, muito pelo contrário. São Paulo, Enigma, 2012.

ScotT, Joan Wallach. A Invisibilidade da Experiência. Projeto História, n. 16, PUC, São Paulo, fev., 1998, pp. 297-325.

SCOTT, Joan Wallach. Fantasy echo: história e a construção da identidade. Labrys, estudos feministas, n. 1-2, jul./dez., 2002.

SCOTT, Joan Wallach. Gênero: uma categoria útil de análise histórica. Educação \& Realidade. vol. 20, n. 2, jul./dez., 1995.

SILVA, Cidinha. As lições da campanha \#SeráQueÉRacismo a um país que não se assume racista. Portal DCM, 2015. Disponível em: https://www.diariodocentrodomundo.com.br/as-licoes-da-campanhaseraqueeracismo-a-um-pais-que-nao-se-assume-racista-por-cidinha-da-silva/ Acesso em: 02 ago. 2016.

VAN DIJCK, J. La cultura de la conectividade: una historia crítica de las redes sociales. 1 ed. Buenos Aires, Siglo Veintiuno Editores, 2016. 